\title{
Research and Application of Guidance Project-teaching Method in Digital Electronic Technology Teaching
}

\author{
Xuemei BAI, Bin GUO, Ziqiang HAO \\ Electrical and Electronic Experimental Teaching Center, Changchun University of Science and Technology, \\ Changchun, China
}

\begin{abstract}
The paper presents a guidance project-teaching method and applied it to the digital electronic technology teaching based on the traditional project-teaching method and the characteristic of undergraduate education. Facts have shown that the guidance project-teaching method can organically combine theory teaching with practice teaching, as well as the each link of practical teaching during the curriculum teaching. The teaching method can reinforce the students' understanding of the whole curriculum of digital electronic technology and it can also be beneficial for cultivating the students to construct scientific thinking model and overall engineering planning ideas.
\end{abstract}

KEYWORD: guidance; project-teaching method; digital electronic technology

\section{INTRODUCTION}

Digital electronic technology, with strong theory and practice, is an important specialized basic course for students of electrical and information majors and it is an important support for follow-up courses. The paper presents guidance project-teaching method for digital electronic technology curriculum based on the curriculum characteristics of plenty of knowledge points and strong applicability of modules, with a view of optimizing the whole teaching process and improving students' understanding of the entire curriculum contents.

The traditional teaching of digital electronic technology is carried out as the order of book's knowledge systems. All aspects of the experimental program, which includes circuit experiments, EDA design experiments and curriculum design are relatively isolated (Tan, 2009). Therefore, students' understanding for the digital electronic technology curriculum remained mostly at the level of "points" (knowledge) and it's difficult to form an integral thinking. This leads to lack of comprehensive and design ideas and it is not conducive for students to form the overall project planning idea.

Guidance project-teaching method would divide reasonably the integrated design parts into some modules and put those modules in every teaching process, then at the comprehensive practical period the modules will be integrated and extended by students. Thus, students' understanding for the curriculum contents will be raised from "point" level to "surface" level and it will play a positive role in building scientific thinking modes (Li, 2005).

\section{CONNOTATION AND SIGNIFICANCE OF THE GUIDANCE PROJECT-TEACHING METHOD}

\subsection{Characteristic of traditional project-teaching method}

Project-teaching method was germinated from labor education ideas in Europe and it is a teacher-led and student-centered new curriculum model with projects as media, ability as targets and society needs as background. Project-teaching method is a teaching activity carried out through the implementation of both teachers and students. It is based on a typical project as the core and divided the project down into different stages, different modules and different tasks, which allowed students to apply what they have learned to solve problems independently (Zhou, 2010). Its main drawback is that it is centered as the project, subproject, module or task and driven by results or stage outcomes, which is lack of mechanisms and measures to stimulate and guide students to actively participate in teaching process.

\subsection{Connotation of guidance project-teaching method}

(1) Background of guidance project-teaching method Teaching process emphasizes continuity and 
succession during undergraduate teaching process. Therefore, the project-teaching method should not be directly applied in the undergraduate teaching and the guidance pedagogy should be introduced in accordance with the curriculum arrangements and knowledge convergence requirements. The subproject should be carried out ahead and the modules should be built and extended autonomously by students (Zhang, 2005). Throughout the teaching design and arrangements, the students' core competencies of electrical information majors are analyzed and the premise is to master the basic knowledge and ability. The curriculum knowledge points are summarized and final experimental projects are divided into multiple subprojects consistent with the course content. At the end of the theory course, students select comprehensive design experiment content and built autonomously the modules and expand them appropriately with topdown approach to complete the whole project.

(2) Characteristic of guidance project-teaching method

The characteristic of guidance project-teaching method is to combine the theory courses with experiment courses and combine the various experimental methods with experimental methods to make organic convergence of each module and carry out the teaching process, thus to constitute a modern teaching chain with coherence of knowledge. Teaching mode of theory and practice integration will be built gradually by setting all levels and kinds of experimental teaching projects and teaching, learning and implementation are integrated as a whole to improve students' practical ability and creative ability and to establish the dominant position of student learning (Zheng, 2004).

(3) Links of guidance project-teaching method

There are some aspects in the guidance projectteaching method including project planning, subsplit, teaching targets, teaching effects examination and teaching outcome assessment. Teaching programs are designed from the basic project to the design project, the ability exercise is to train students from a single skill to comprehensive skills and the project teaching is to enhance students' cognitive ability and mastery in progressive ways

(4) Goals for guidance project-teaching method

Its goal is to improve students' understanding of overall curriculum, to build students' modular design ideas and rigorous scientific thinking and improve students' ability of engineering practice.

\section{IMPLEMENTATION STRATEGY OF GUIDANCE PROJECT-TEACHING METHODS}

The project-teaching method is expended by introduction of hierarchy and guidance according to the course characteristics and teaching objectives. Hierarchical design helps students at different ability levels find better learning entry points and guidance makes the knowledge system more complete. Integration of subprojects can improve the teaching efficiency and overall control ability (Ruan, 2006). In addition, during the project teaching open mode is employed, which includes the choice of teaching content as well as the choice of experimental time. Thus, students can have more freedom and autonomy to carry out the project, which will be benefit for students to foster the professional interests and self-confidence. There are four main factors, as follows, in the course of guidance projectteaching method implementation.

\subsection{Reasonable dividing teaching projects}

Subprojects should be closely associated with the knowledge points of the curriculum and they should also be closely associated with the original experiments to carry out the integration and continuity of curriculum system. Meanwhile, the extension of the subprojects should also be considered in depth in order to facilitate comprehensive projects' combination and extension.

\subsection{Comprehensive monitoring teaching process}

Guidance project-teaching method monitors the whole teaching process in a full range. Theory teaching should strengthen the training of integration capacities and infiltration of teaching programs and the experiment teaching should consider the requirements of interface and scalability aspects.

\subsection{Reasonable goals for stratification}

The stratification goals should be set reasonably and the hidden stratification should be employed to take into account all students, while the other goals of higher requirements can be set to develop quality. "Differences project teaching" is a reflection of a student-centered curriculum models and taking into account the differences between the concept of students and it is a kind of curriculum thoughts [3]. Requirements on the content of subprojects and comprehensive projects are set as mandatory and optional to provide students with choose space. Students would be intrigued by the contents of a comprehensive projects, which will guide students' efforts to a higher level objects.

\subsection{High requirements of teaching standards}

Guidance Project-teaching Method puts forward higher requirements for teachers in education philosophy and professionalism. Teachers firstly 
need to have an overall grasp of the course contents and subprojects plan and then split the contents into every teaching part. Meanwhile, education and guidance for students are critical. Throughout the teaching activities, students should be in a positive state of creation and teachers' task is to guide students to explore ways and means to acquire knowledge and skills, which can cultivate students' creativity. Teaching activities should not remain at the level of the existing development of students, but take appropriate methods to inspire students and a series of internal development process and complete a higher level of knowledge.

\section{EVALUATION AND ASSESSMENT OF GUIDANCE PROJECT-TEACHING METHOD}

According to the teaching characteristics of the course, the students' interest points through investigation and the existing training programs, the practice teaching projects are designed and built with the subprojects. Here, we focus on the practical integration of resources, including small and medium-scale integrated circuit experiments, EDA simulation experiments and curriculum design, so that students can apply the various experimental means to the utmost. The reasonable teaching evaluation system is constructed based on the overall implementation of subprojects and integration projects and the assessment process is wellorganized (Luo, 2009).

Theoretical examination includes final examination and routine examinations. Written examination is predominant in final examination and we adhere the principle of separation between teaching and examination. The routine test includes stage tests, assignments, attendance, answering questions and so on. The assignments do not only stay on memorizing and understanding of knowledge, the questions, discussion and other forms are employed with specific application examples. Heuristic guidance is adopted and the application examples of each project are combined, then students should implement the simulation after theoretical design and actual experiments. The final experimental evaluation includes manipulative testing, simulation and defense and so on.

Since the assessment' targets and steps are more specific, the assessment plays a good role in monitoring students' learning. At the same time, the students' enthusiasm has been effectively mobilized and their professional interests have been boosted because of the whole projects implementation.

\section{CONCLUSION}

Guidance project-teaching method is a useful exploration and in-depth study of our digital electronic technology teaching group during the construction of the outstanding class of Jilin Province. The key of the digital electronic technology is to develop students' knowledge system and cultivate students' practical ability according to the course's strong theoretical and practical characteristics,.During the research of guidance project-teaching method, we try to improve the teaching effectiveness and cultivate students' capability based on the national experimental teaching demonstration center and students carried out the learning activities under the project driving, finished projects from simple parts to the complex ones, from easy to difficult and completed the practical aspects of digital electronic technology step by step.

Guidance Project-teaching Method used in digital electronic technology course, is suitable for teachers' teaching and students' learning, which has a strong impetus to the teaching reform and teaching practices and makes the digital electronic technology teaching form a teaching model with distinct characteristics. It plays an important role for students in the cultivation of engineering practice and innovative ability.

\section{REFERENCES}

[1] Li Zheng, Shenguo Ding, Shiping Yang, Study on the Teaching Method of Behavioral Guidance. Journal of Hebei Energy Institute of Vocation and Technology, 2004, 04:20-22.

[2] Hongying Tan \& Zhengbing Zhang, Non-electrical digital circuits Innovative Teaching Research. China Modern Education Equipment, 2009, 7:86-87

[3] Huming Zhou, Application of Project-teaching Method and Analysis of Typical Cases. China Modern Education Equipment, 2010, 13:6-8

[4] Peng Zhang, Discussion on Guidance Teaching Method of Electronic Technology Course. Journal of North China Institute of Astronautic Engineering, 2005, 35:67-71.

[5] Yonguan Li, Conduct guided" method and its application in the "module" Teaching, Journal of Huangshan University, 2005, 02:111-112.

[6] Youde Ruan, Multi-leveled Teaching in Class in Electrical Practice Training Teaching. JOURNAL OF EEE, 2006, 28:25-27

[7] Yunhu Luo, Lidong Xing, Qin Wang, The Reform of Curriculum Project Based on Project Teaching Method. JOURNAL OF EEE, 2009, 31 (6):14-15 